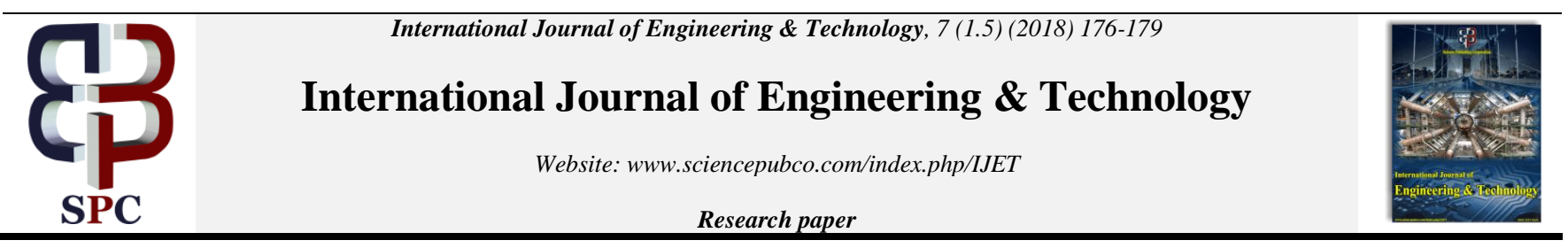

\title{
Optimization and analysis of high gain wideband microstrip patch antenna using genetic algorithm
}

\author{
Raj Gaurav Mishra*, Ranjan Mishra, Piyush Kuchhal and N. Prasanthi Kumari \\ School of Engineering, University of Petroleum and Energy Studies, CoES, P.O. Bidholi, Via Prem Nagar, \\ Dehradun-248007, Uttarakhand, India. \\ *Corresponding author E-mail: rgmishra@ddn.upes.ac.in
}

\begin{abstract}
Microstrip antennas that can operate in single and multiple frequency bands are required in various wireless communication devices. A single patch, square shaped microstrip patch antenna having high directivity and gain is proposed in this paper. The geometry of proposed antenna is optimized using Genetic Algorithm (GA) to operate in X-Band for wideband applications. The proposed antenna design exhibits a wide operating bandwidth $550 \mathrm{MHz}$ (simulated) and $450 \mathrm{MHz}$ (measured), high gain and directivity of about $8.35 \mathrm{~dB}$ (simulated) making it suitable for wideband applications. The proposed antenna design works in X-band which has weatherproof characteristics and supports easy communication of voice, data, images and HD videos. The attractiveness of the GA design over the traditional design methods is its ability to achieve the desired performance by using a simple design of single patch antenna.
\end{abstract}

Keywords: Microstrip Patch Antennas; Genetic Algorithm; GA; Antenna Optimization; High Gain.

\section{Introduction}

Microstrip patch antennas are of low profile, simple and inexpensive to manufacture, conformable to any surfaces, compatible with MMIC designs, mechanically robust, can be mounted on rigid surfaces. They show good flexibility in their impedance characteristics, operating frequency and polarization pattern [1]-[3] the moment their patch shape and mode are specified. These antennas find their usefulness in all bands under super high frequency. The sizing control of microstrip antennas are becoming an essential design consideration caused by rapid reduction in the size of gadgets used for personal communications. Although, suitable antenna design has become tight and difficult in the recent years with built-in trade-offs that are present between the selection of parameters like bandwidth, directivity, gain, radiation pattern, etc, making design a lengthy process. Optimization techniques are evolving as a fast method of realization in the field of engineering [4]. In recent times, numerous methods are used to optimize its performance by using pre-existing optimization techniques e.g. particle swarm optimization (PSO) [5] and genetic algorithm [6][9]. Genetic algorithm (GA) is an efficient optimization method, having its applications in the open areas of Electromagnetics [10]. GA based on the Darwinian principles of natural evolution and selection has been utilized to improve the performance of microstrip antenna and their parameters like bandwidth, directivity, gain, size [6]-[12] etc.

$\mathrm{X}$-band have exceptionally high link availability in all weathers including rain, sand storm and other challenging conditions. $\mathrm{X}$ band supports the communication of voice, data, images and HD video.

\section{Microstrip Antenna Design, Results and Discussion}

Selection of the operating frequency and substrate are the initial steps in the designing of the microstrip antenna. The operating frequency in the proposed design is $11 \mathrm{GHz}$, within the X-band of super high frequency. This frequency band is the most durable band in the wire-less communication. The commercially available substrate material RT/duroid with height of $1.574 \mathrm{~mm}$ has a dielectric constant of 2.2. Using the equations for obtaining the dimension of the microstrip antenna [1], the initial antenna was designed having the patch length of $8.08 \mathrm{~mm}$ and patch height of $10.77 \mathrm{~mm}$. GA was applied to optimize the antenna design to achieve high gain and directivity. The square shaped antenna having edge size of $8.08 \mathrm{~mm}$ is obtained as a result of GA based optimization. The code for GA algorithm is integrated with HFSS environment using MATLAB. A block diagram of a GA based simple optimizer is shown in Figure 1. GA parameters such as string of bits (chromosome), population size and total number of generations used for the purpose of optimization of antenna geometry parameters to achieve higher bandwidth is discussed in Table 1. The substrate is also of square in shape with the edge dimension of $38.4 \mathrm{~mm}$. The square patch and the transmission line is connected with an stub for perfect impedance matching $[1,15]$. The overall dimension of the proposed antenna is shown in Figure 2. 


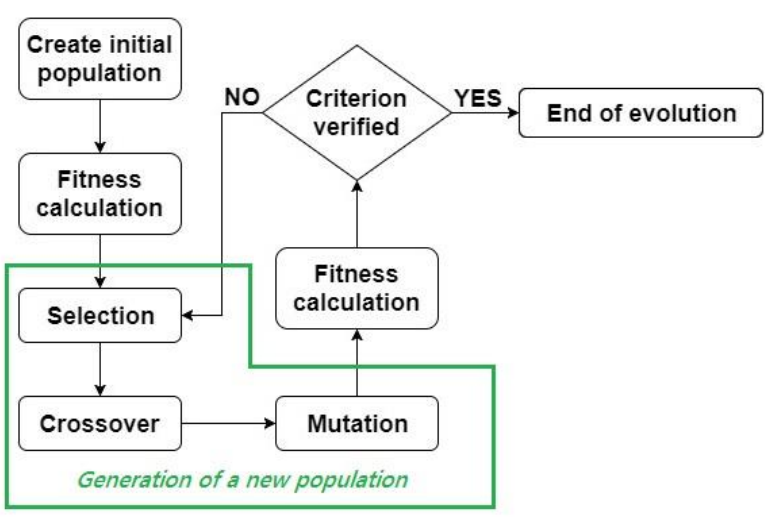

Fig. 1: A simple genetic algorithm optimizer [18].

Table 1: GA Parameters used for the purpose of antenna design

\begin{tabular}{|l|l|}
\hline GA Parameters & Values \\
\hline Number of decision variables & 34 Bit \\
Population type & Bit String \\
Population Size & 200 \\
Selection & Roulette \\
Scaling & Rank \\
Reproduction Elite Count & 2 \\
Crossover Fraction & 0.8 \\
Crossover & Single Point Crossover \\
Mutation & Uniform $(0.01)$ \\
Migration & Both front and back \\
Penalty factor & 100 \\
Initial Penalty & 10 \\
Total number of Generations & 200 \\
\hline
\end{tabular}

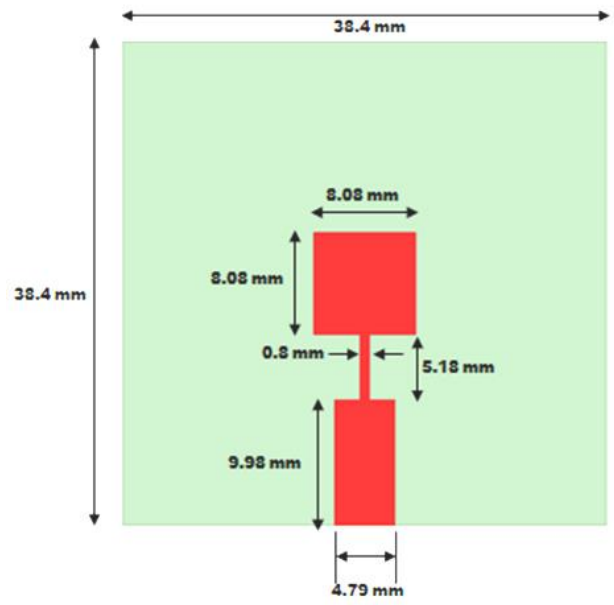

Fig. 2: Proposed antenna with dimensions.

The simulation of the proposed antenna is carried using HFSS soft-ware of Ansoft. Mechanical etching using computer-aided technique is employed in the fabrication of the antenna. The Return losses (S11) of the fabricated antenna are measured using vector network analyser. Figure 3 shows the fabricated antenna. The simulated and measured return losses (S11) with respect to the frequency (X-band) are presented in Figure 4. The return loss (S11) curve is a smooth and sharp one with the resonant frequency at $10.9 \mathrm{GHz}$ having $32 \mathrm{~dB}$ (simulated results) and $27 \mathrm{~dB}$ (measured results) of reflection coefficients. The proposed antenna shows $550 \mathrm{MHz}$ (simulated re-sults) and $450 \mathrm{MHz}$ (measured results) of bandwidth. Measured and simulated result are almost identical (refer Figure 4).

Two dimensional (2D) and three dimensional (3D) radiation patterns are plotted and shown in Figure 5. A plot of gain and directivity over the X-Band range $(8 \mathrm{GHz}$ to $12 \mathrm{GHz})$ of the antenna is presented in Figure 6. It shows that the proposed antenna has a very high gain and directivity. At the peak resonant frequency of $10.9 \mathrm{GHz}$, proposed antenna exhibits a gain of $8.328 \mathrm{~dB}$. The maximum radiation intensity of the proposed antenna is 3.89 $\mathrm{mW} / \mathrm{str}$. The 2D plot (shown in Figure 5) also revealed almost zero back lobes (no back radiations) for the proposed antenna. In the next section, the impedance of the antenna is calculated using transmission line model.

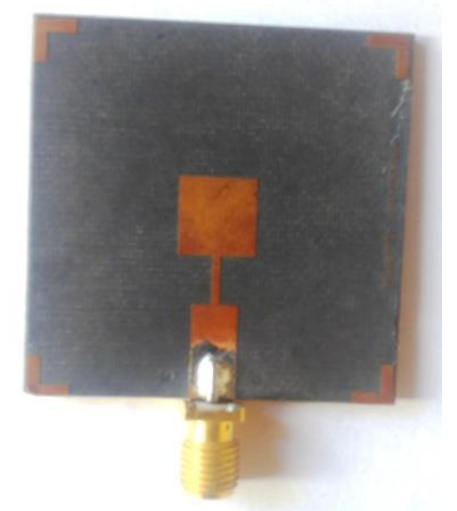

Fig. 3: Image of the fabricated antenna (top view).

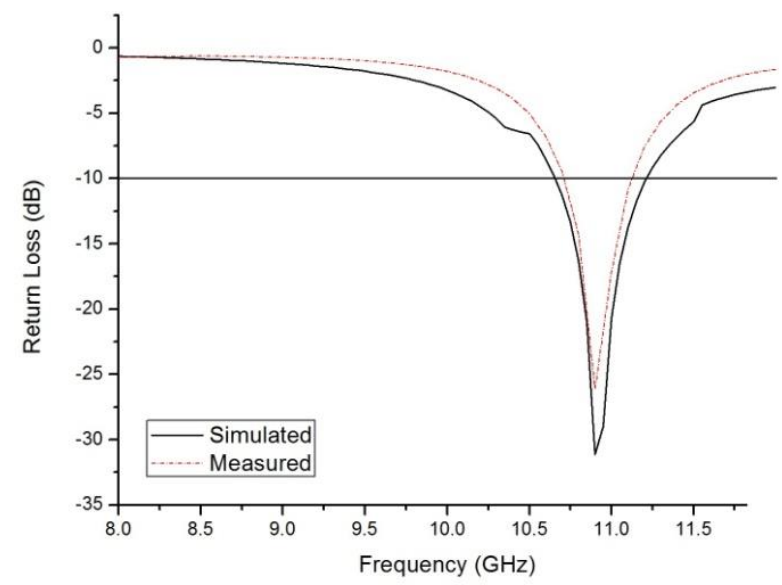

Fig. 4: Measured and simulated return losses (S11) of the antenna.

\section{Impedance calculation}

Impedance bandwidth is an important identity in the realistic of antenna [14]. The analysis of the microstrip antenna can be mathematically done with either transmission line modelling [15] or using differential time modelling [16]. The patch of the antenna is represented as a parallel-plate transmission line. It is comprising of two radiating slots, each of width $\mathrm{W}$ and height $\mathrm{h}$. This model provides a relatively fair insight into the behaviour of the patch antenna. The general representation of a 3-port transmission line [15] of the microstrip antenna is represented in Figure 7.

The admittance matrix of 3-port circuit is given as follows:

$[Y]=\left[\begin{array}{ccc}Y_{S}+Y_{c} \operatorname{coth}\left(\gamma L_{1}\right) & -Y_{m} & -Y_{c} \operatorname{csch}\left(\gamma L_{1}\right) \\ -Y_{m} & Y_{S}+Y_{c} \operatorname{coth}\left(\gamma L_{2}\right) & -Y_{c} \operatorname{csch}\left(\gamma L_{2}\right) \\ -Y_{c} \operatorname{csch}\left(\gamma L_{1}\right) & -Y_{c} \operatorname{csch}\left(\gamma L_{2}\right) & Y_{c} \operatorname{coth}\left(\gamma L_{1}\right)+Y_{c} \operatorname{coth}\left(\gamma L_{2}\right)\end{array}\right]$

Here, $Y c$ is the characteristic admittance of the microstrip line formed by the patch. And, $\mathrm{Zc}=1 / \mathrm{Yc}$ is the characteristic impedance. Taking the result of the generalized solution of [Y], the values of characteristic impedance [17] (Zc) in terms of antenna parameters is given in equation 1 .

$Z_{c}=\frac{120 \pi / \sqrt{\varepsilon_{e f f}}}{\frac{W}{h}+1.393+0.667 \ln \left(\frac{W}{h}+1.444\right)}$ 


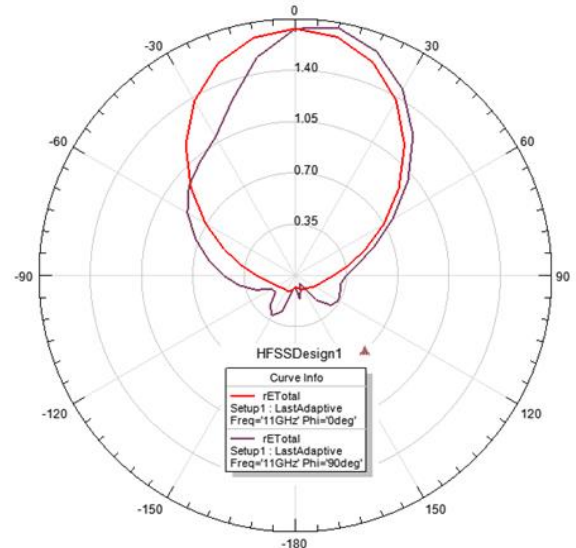

(A)

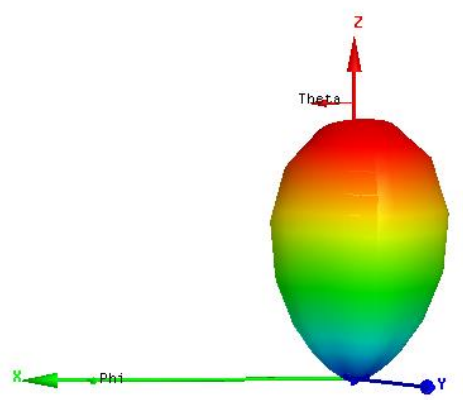

(B)

Fig. 5: (A) 2D radiation patterns for $\mathrm{F}$ at 0 degree and 90 degree; (B) 3D Radiation Pattern

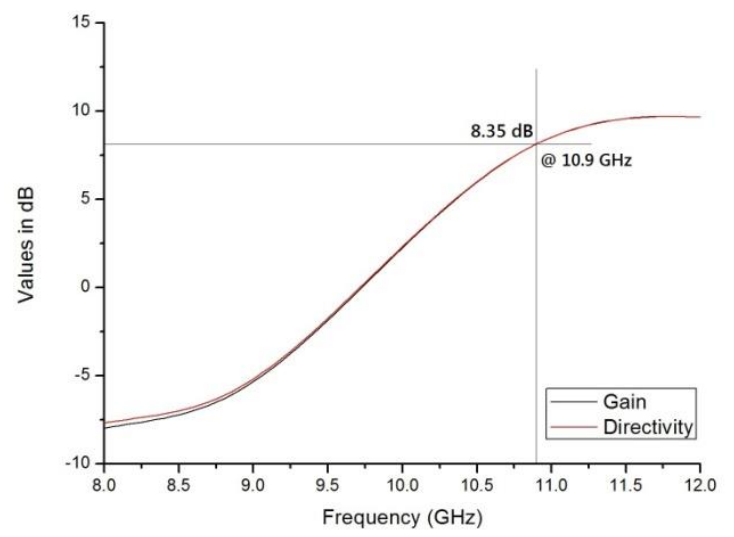

Fig. 6: Plot of gain and directivity of the proposed antenna

Using the value of the dielectric constant (e), height of substrate (h) and width of patch (W), the measured value of impedance comes out to be $52.33 \mathrm{~W}$, which is exactly close to the theoretical value of $50 \mathrm{~W}$. This matching of impedance is the reason for high gain and directivity of the proposed antenna.

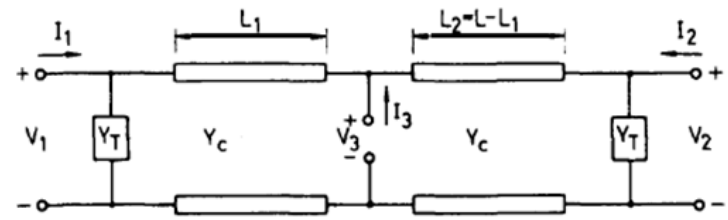

Fig. 7: 3-port transmission line [15]

\section{Conclusion}

A square shaped, single-patch microstrip antenna having high gain and directivity (both of $8.35 \mathrm{~dB}$ ) is presented in this paper by applying genetic algorithm technique to optimize the geometry of the rectangular patch. The substrate used to design and fabricate the antenna is RT/duroid with low dielectric constant. A substrate with low dielectric constant is helpful in increasing the radiation of the wave intensity and thus helpful in high directivity. This consequently increases the gain. The simulation and measured results are almost identical and displaying wide bandwidth in $\mathrm{X}$ band. The calculated impedance using transmission-line modeling is $52.33 \mathrm{~W}$. Impedance calculations along with the proximity of simulation and a measured result authenticates the design procedure of the antenna. The simple shape and small size of the proposed antenna is obtained by optimization using genetic algorithm. The novelty of this work is the simplicity of the antenna design making it easy to fabricate.

\section{Acknowledgement}

This research work is supported by the University of Petroleum and Energy Studies at Dehradun, Uttarakhand, India.

\section{References}

[1] R. Garg, P. Bhartia, I. Bahl, A. Ittipiboon, Microstrip Antenna Design Handbook, Artech House, 2001.

[2] R. Mishra, An Overview of Microstrip Antenna, HCTL Open International Journal of Technology Innovations and Research (IJTIR), Volume 21, Issue 2, August 2016.

[3] Prasanthi N., Praful Ranjan, Piyush Kuchhal, Design and Fabrication of Miniaturized Metamaterial Antenna for Mobile and Wireless Applications, International Journal of Advances in Engineering \& Technology, ISSN: 2231-1963, pp. 1687-1692, Sept. 2013.

[4] A.R. Ayad, H.A. Awad, A.A. Yassin, Parametric analysis for genetic algorithms handling parameters, Alexandria Engineering Journal, Volume 52, Issue 1, 2013, Pages 99-111, ISSN 1110-0168.

[5] Lee, K. C., J. Y. Jhang, Application of particle swarm algorithm to the optimization of unequally spaced antenna arrays, Journal of Electromagnetic Waves and Applications, Vol. 20, No. 14, 2001 2012, 2012.

[6] Soontornpipit, P., C. M. Furse, Y. C. Chung, Miniaturized biocompatible microstrip antenna using genetic algorithms, IEEE Trans. Antennas Propag., Vol. 53, No. 6, 1939-1945, 2005.

[7] Herscovici, N., M. F. Osorio, and C. Peixeiro, Miniaturization of rectangular microstrip patches using genetic algorithms, IEEE Antennas Wireless Propag. Letters, Vol. 1, No. 1, 94-97, 2002.

[8] F. J. Villegas, T. Cwik, Y. Rahmat-Samii, M. Manteghi, A Parallel Electromagnetic Genetic Algorithm Optimization (EGO) Application for Patch Antenna Design, IEEE Trans. Antennas Propagat., vol. 52, no. 9, pp. 2424-2435, Sept. 2004.

[9] H. Choo, A. Hutani, L.C. Trintinalia, and H. Ling, Shape optimisation of broadband microstrip antennas using genetic algorithm, IET Electronics Letters, vol. 36, issue 16, pp. 2057-2058, Dec. 2000.

[10] Johnson, J. M. and Y. Rahmat-Samii, Genetic algorithms in engineering elecromagnetics, IEEE Trans. Antennas Propag., Vol. 39 , No. 10, 7-21, 1997

[11] Weile, D. S. and E. Michielssen, Genetic algorithm optimization applied to electromagnetics: A review, IEEE Trans. Antennas Propag., Vol. 45, No. 3, 343-353, 1997.

[12] Jayasinghe, J. M. J. W., J. Anguera, D. N. Uduwawala, Genetic algorithm optimization of a high-directivity microstrip patch antenna having a rectangular profile, Radioengineering, Vol. 22, No. 3, 1-4, 2012.

[13] D.E. Goldberg, Genetic Algorithms in search Optimization \& Machine learning., Pearson India 2004.

[14] M. John and M. J. Ammann, Optimisation of Impedance Bandwidth for the Printed Rectangular Monopole Antenna, Microwave and Optical Technology Letters, vol. 47(2), pp. 153-154, Oct. 2005.

[15] Gupta, K.C., Garg, R., Bahl, I., Bhartia, P., Microstrip Lines and Slotlines, 2nd ed., Artech House, USA, 1996, pp. 282-286.

[16] R.K. Chaurasia, Vishal Mathur, R.L. Pareekh, Mohammad Tamsir, Vineet K. Srivastava, A computational modelling of micro strip 
patch antenna and its solution by RDTM, Alexandria Engineering Journal, 2017, ISSN 1110-0168.

[17] R. Mishra, J. Jayasinghe, R. G. Mishra, P. Kuchhal, Design and Per-formance Analysis of a Rectangular Microstrip Line Feed Ultra-Wide Band Antenna, International Journal of Signal Processing, Image Pro-cessing and Pattern Recognition Vol.9, No.6, pp.419426, 2016.

[18] M. Lamsalli, A. El Hamichi, M. Boussouis, N. Amar Touhami, and T. Elhamadi, Genetic algorithm optimization for microstrip patch antenna miniaturization, Progress In Electromagnetics Research Letters, Vol. 60, 113-120, 2016. 